\title{
Altered lung structure and function in mid-childhood survivors of very preterm birth
}

\author{
Shannon J Simpson, ${ }^{1,2}$ Karla M Logie, ${ }^{1,3}$ Christopher A O'Dea, 1,4,5 \\ Georgia L Banton, ${ }^{1}$ Conor Murray, ${ }^{6}$ Andrew C Wilson, ${ }^{1,2,3,4,5}{ }^{\mathrm{J}} \mathrm{Jane} \mathrm{Pillow}^{7}$ \\ Graham L Hall ${ }^{1,2,5}$
}

- Additional material is published online only. To view please visit the journal online (http://dx.doi.org/10.1136/ thoraxjnl-2016-208985).

For numbered affiliations see end of article.

\section{Correspondence to} Professor Graham L Hall, Children's Lung Health, Telethon Kids Institute, PO Box 855, West Perth, WA 6872, Australia; graham.hall@telethonkids. org.au

SJS and KML contributed equally.

Received 3 June 2016 Revised 19 December 2016

Accepted 1 January 2017

Published Online First

24 January 2017

\section{Linked}

- http://dx.doi.org/10.1136/ thoraxjnl-2016-208524 - http://dx.doi.org/10.1136/ thoraxjnl-2016-209291

CrossMark

To cite: Simpson SJ,

Logie KM, O'Dea CA, et al.

Thorax 2017;72:702-711.

\section{ABSTRACT}

Rationale Survivors of preterm birth are at risk of chronic and lifelong pulmonary disease. Follow-up data describing lung structure and function are scarce in children born preterm during the surfactant era.

Objectives To obtain comprehensive data on lung structure and function in mid-childhood from survivors of preterm birth. We aimed to explore relationships between lung structure, lung function and respiratory morbidity as well as early life contributors to poorer childhood respiratory outcomes.

Methods Lung function was tested at 9-11 years in children born at term (controls) and at $\leq 32$ weeks gestation. Tests included spirometry, oscillatory mechanics, multiple breath nitrogen washout and diffusing capacity of the lung for carbon monoxide. Preterm children had $\mathrm{CT}$ of the chest and completed a respiratory symptoms questionnaire.

Main results 58 controls and 163 preterm children (99 with bronchopulmonary dysplasia) participated. Preterm children exhibited pulmonary obstruction and hyperinflation as well as abnormal peripheral lung mechanics compared with term controls. $\mathrm{FEV}_{1}$ was improved by $0.10 \mathrm{z}$-scores for every additional week of gestation ( $95 \% \mathrm{Cl} 0.028$ to $0.182 ; p=0.008)$ and by $0.34 \mathrm{z}$-scores per $z$-score increase in birth weight $(0.124$ to $0.548 ; p=0.002$ ). Structural lung changes were present in $92 \%$ of preterm children, with total CT score decreased by $0.64(-0.99$ to $-0.29 ; p<0.001)$ for each additional week of gestation. Obstruction was associated with increased subpleural opacities, bronchial wall thickening and hypoattenuated lung areas on inspiratory chest CT scans $(p<0.05)$.

Conclusions Abnormal lung structure in mid-childhood resulting from preterm birth in the contemporary era has important functional consequences.

\section{INTRODUCTION}

Bronchopulmonary dysplasia (BPD) is one of the most significant complications of preterm birth. BPD was described nearly 50 years ago in infants suffering from severe respiratory distress syndrome following prolonged treatment with mechanical ventilation and high concentrations of inspired oxygen $\left(\mathrm{O}_{2}\right) \cdot{ }^{1}$ Infants with BPD had abnormal chest radiographs, including areas of lung collapse alternating with hyperinflation and severe emphysema, as well as histopathological changes

\section{Key messages}

What is the key question?

- What is the impact of contemporary preterm birth on lung structure and lung function during mid-childhood, and what factors predict poorer outcomes for these children?

\section{What is the bottom line?}

- Infants born very preterm are at significant risk of ongoing lung disease with considerable structural abnormalities, lung function deficits and consequent respiratory symptoms reported in mid-childhood.

\section{Why read on?}

- These comprehensive data examining the lung health of children born preterm, in the contemporary era, raise concerns about the long-term lung health of a subset of this population. Structural lung abnormalities in children born preterm were common and associated with more obstructive lung function and more severe respiratory symptoms and may imply active lung disease. What this means for the health of these children as they age must be a priority for future investigations.

consistent with interstitial thickening, lung fibrosis and smooth muscle hypertrophy. ${ }^{1}$

Neonatal critical care has evolved considerably over the past few decades: the implementation and standardisation of postnatal surfactant therapy, increased use of antenatal maternal corticosteroids and the development of less aggressive ventilation strategies have altered both the nature of and the infant population affected by BPD. ${ }^{2}$ Whereas the initial report of BPD described an infant population with a mean gestational age (GA) of 34 weeks, ${ }^{1}$ babies born in the early saccular and even the late cannalicular stages of lung development (ie, <28 weeks GA) now often survive in middle-income and high-income countries. ${ }^{3}$ Thus, a 'new' BPD pathophysiology has emerged, characterised by fewer, larger alveoli resulting in reduced surface area for gas exchange and dysmorphic pulmonary capillary growth. ${ }^{45}$

Survivors of preterm birth have a high burden of respiratory disease in the first years of life. $^{6}{ }^{7}$ 
Beyond infancy, existing follow-up data of new BPD largely describe small or selected populations of children with the most severe neonatal disease or survivors of extreme prematurity. ${ }^{8-10}$ Consequently, the lack of comprehensive and appropriately powered assessments of lung structure and function across the spectrum of preterm children render it difficult to determine if the clinical course of contemporary prematurity differs from the early descriptions of BPD.

This study aimed to evaluate lung function, lung structure and the relationship between structure and function in a contemporary population of children born $\leq 32$ weeks gestation. Furthermore, we aimed to elucidate the impact of prematurity and neonatal treatments on lung function and structure findings to provide a comprehensive snapshot of the respiratory system during mid-childhood following preterm birth. We hypothesised that worse lung structure and function at mid-childhood would be associated with a more severe neonatal course. Second, we hypothesised that pulmonary function deficits would be underpinned by structural abnormalities of the lung.

\section{METHODS}

\section{Participants}

Preterm children, with and without a neonatal classification of BPD, and healthy term-born controls were studied at 9-11 years of age. Preterm and term children who had previously been studied by our group at 4-8 years ${ }^{11}$ were prioritised for recruitment to this study. The study was then supplemented with additional participants living in the Perth metropolitan region. Children born at King Edward Memorial Hospital (KEMH) $\leq 32$ weeks gestation between 1997 and 2003 were recruited from the KEMH neonatal database. BPD was defined as at least 28 days supplemental oxygen requirement as assessed at 36 weeks postmenstrual age. ${ }^{12}$ Healthy term controls were at least 37 weeks completed gestation with no lifetime history of cardiopulmonary disease or recurrent respiratory symptoms. Written informed parental/guardian consent and child assent were obtained prior to data collection. Approval was obtained from the Princess Margaret Hospital for Children Ethics Committee (EP1760).

\section{Assessment of lung function}

Assessment of lung function included spirometry, multiple breath nitrogen washout, diffusing capacity of the lung for carbon monoxide (Sensormedics Vmax, Yorba Linda, California, USA) and the forced oscillation technique (FOT) (I2M, Chess Medical, Ghent, Belgium). Lung function tests were performed according to American Thoracic Society/ European Respiratory Society standards. ${ }^{13-16}$ Lung function outcomes were expressed as z-scores to adjust for the relevant anthropometric factors, with the exception of Lung Clearance Index (LCI), residual volume (RV)/total lung capacity (TLC) and functional residual capacity (FRC)/TLC that are independent of anthropometrics. ${ }^{17-20}$

\section{Assessment of lung structure}

CT images of the chest were acquired in children born preterm during both inspiration and expiration. Inspiratory images spanned from the lung apex to diaphragm at $10 \mathrm{~mm}$ intervals. Three expiratory images were collected at the anatomical points of the tracheal carina and the midpoints between the tracheal carina and the lung apex, and tracheal carina and diaphragm (Philips Brilliance 64; Philips Medical Systems, the Netherlands). The chest CT scans were consensus scored in the same scoring session by a specialist paediatric thoracic radiologist $(\mathrm{CM})$ and a paediatric respiratory physician $(\mathrm{ACW})$ using the scoring system described by Aukland et al. ${ }^{21}$ Scorers were blinded to severity of neonatal lung disease. Healthy controls did not undergo chest CT.

\section{Other assessments}

Respiratory morbidity in the 3 months prior to the visit was assessed via a questionnaire. ${ }^{22}$ Neonatal data extracted from the KEMH neonatal database and patient medical records included GA, birth anthropometrics, antenatal steroid exposure, confirmed sepsis during the birth admission, number of surfactant doses, days of supplemental oxygen, mechanical ventilation and CPAP.

\section{Study power and statistical analysis}

Normally distributed data are presented as means and SDs. Non-normally distributed data are presented as medians and IQR. Differences in lung function between groups were analysed by one-way analysis of variance with post hoc comparisons. The Mann-Whitney $U$ test or independent samples t-test was used for the assessment of differences between groups for all other outcomes, depending on normality of the data. The relationships between neonatal factors and lung function or lung structure were initially assessed using univariate linear regressions. Neonatal factors with significant univariate correlation to structure/function outcomes were included in subsequent stepwise multiple linear regressions. Multicollinearities between the neonatal predictors were identified and adjusted for by using residuals of independent regressions of the collinear variables. For example, the independent impact of mechanical ventilation on lung structure/function was determined from the residual of the regression between GA and mechanical ventilation.

A minimum sample size of 75 preterm children provides at least $80 \%$ power for a multiple linear regression to detect a 0.2 z-score difference in lung function with six predictors. Significance is considered at the 5\% significance level. All data were analysed using SPSS (V.22; IBM, Chicago, Illinois, USA).

\section{RESULTS}

\section{Study participants at follow-up visit}

There were no anthropometric differences between the term born controls $(\mathrm{n}=58)$ and preterm children $(\mathrm{n}=163)$ at the time of the follow-up assessment (table 1). However, children with BPD $(n=99)$ were shorter $(\mathrm{p}<0.001)$ than term-born children and lighter $(p=0.001)$ than their term and preterm peers without BPD. Parents reported respiratory symptoms such as wheeze, shortness of breath and excessive cough without colds in approximately half of all children born preterm in the 3 months prior to the visit (table 1 ).

The preterm cohort was born at a median (IQR) gestation of $28(25.0,29.6)$ weeks (table 2). As expected from the definition of BPD, children with BPD required a longer duration of oxygen supplementation and increased days of respiratory support $(\mathrm{p}<0.001)$ during the neonatal period than preterm children without BPD. The BPD group also had a lower GA and birth weight $(\mathrm{p}<0.001)$; however, there was no difference between birth weight $\mathrm{z}$-score for preterm children with BPD and with those without BPD $(p=0.121)$.

Generalisability of participants to the preterm population Between July 1998 and December 2003, 1316 children were delivered at KEMH $\leq 32$ weeks GA, with $371(28.2 \%)$ of these infants developing BPD. Preterm infants (no BPD) not recruited 
Table 1 Participant demographics at the time of follow-up visit

\begin{tabular}{|c|c|c|c|c|}
\hline & \multirow[b]{2}{*}{ Term controls } & \multirow[b]{2}{*}{ Preterm } & \multicolumn{2}{|l|}{ Preterm } \\
\hline & & & No BPD & BPD \\
\hline Participants, n & 58 & 163 & 64 & 99 \\
\hline Males, n (\%) & $26(45)$ & $100(61)$ & $42(65)$ & $58(59)$ \\
\hline Age (year) & $10.7(0.9)$ & $10.9(0.6)$ & $10.9(0.6)$ & $10.8(0.6)$ \\
\hline Height $(\mathrm{cm})$ & $146.6(9.7)$ & $142.0(8.0)$ & $143.3(9.0)$ & $140.6(8.0)^{*}$ \\
\hline Weight (kg) & $37.4(8.3)$ & $35.6(10.6)$ & $38.9(13.6)$ & $33.5(7.4)^{*} \dagger$ \\
\hline \multicolumn{5}{|c|}{ Symptoms in the 3 months prior to the test visit expressed as $n$ (\% of those completing questionnaire) } \\
\hline Asthma medication usage & - & $47(32.0)$ & $21(38.9)$ & $26(28)$ \\
\hline Respiratory symptoms at rest & - & $26(17.0)$ & $16(26.2)$ & $10(11.9) \dagger$ \\
\hline Respiratory symptoms on exertion & - & $78(51.0)$ & $28(47.5)$ & $50(53.2)$ \\
\hline Any respiratory symptoms past 3 months & - & $80(52.6)$ & $29(49.2)$ & $51(54.8)$ \\
\hline
\end{tabular}

for this study were born at a median (IQR) GA of 30.4 $(28.3,31.3)$ weeks, with a birth weight of $1440(1165,1680) \mathrm{g}$ and required $1(0,3)$ day of supplemental $\mathrm{O}_{2}$. Infants developing BPD during this time were born at $26.6(25.1,28.0)$ weeks GA, weighing $895(705,1055) \mathrm{g}$ and required $75(48,98)$ days supplemental $\mathrm{O}_{2}$. There was no difference in neonatal characteristics for children recruited to this study (table 2), with the exception that recruited preterm children without BPD had slightly lower GA $(29.8 ; 28.3,31.0$ weeks; $p=0.004)$ than the non-recruited cohort.

\section{Lung function in preterm children}

Forced flows and volumes: Preterm children had significantly lower spirometry values $\left(\mathrm{FEV}_{1}, \mathrm{FEF}_{25-75}\right.$ and $\left.\mathrm{FEV}_{1} / \mathrm{FVC}\right)$ than healthy control children (table 3), which were further decreased in those with BPD (see online supplementary table S1). Abnormally low lung function (defined as $\mathrm{FEV}_{1}, \mathrm{FEV}_{1} / \mathrm{FVC}$ or $\mathrm{FEF}_{25-75} \leq-1.96 \mathrm{z}$-scores) was not observed in any of the healthy children, but was observed in $7(13.5 \%)$ of the preterm group without BPD and 37 (46.8\%) of the children with BPD.

Decreased GA and birth weight z-score were associated with lower $\mathrm{FEV}_{1}$ and FVC $\mathrm{z}$-scores in mid-childhood (see figure 1 and online supplementary table S2). Lower forced expiratory flows and volumes $\left(\mathrm{FEV}_{1}\right.$ and $\left.\mathrm{FEF}_{25-75}\right)$ were also observed in children with higher durations of supplemental oxygen and confirmed septicaemia during the neonatal period. Multivariate analysis (see online supplementary table S2) demonstrated that $\mathrm{FEV}_{1} \mathrm{z}$-score was increased by $0.1 \mathrm{z}$-scores for every additional week of gestation $(B=0.105 ; 95 \%$ CI 0.028 to $0.182 ; \mathrm{p}=0.008)$ and improved by increasing birth weight $z$-score $(B=0.336$; $95 \%$ CI 0.124 to $0.548 ; \mathrm{p}=0.002$ ), accounting for $16.9 \%$ of the variation in $\mathrm{FEV}_{1}$ in preterm children. Increasing days of supplemental $\mathrm{O}_{2}$ remained the only weak $\left(\mathrm{R}^{2}=0.070\right)$ independent predictor of reduced $\mathrm{FEF}_{25-75} \mathrm{Z}$-score in a multivariate analysis such that each additional week of oxygen was associated with a 0.056 decrease in mid-expiratory flows after accounting for GA and days of mechanical ventilation $(B=-0.008,95 \% \mathrm{CI}$ -0.016 to $-0.000 ; \mathrm{p}=0.040)$.

Lung volumes by multiple breath washout: Very preterm children had increased FRC $\mathrm{z}$-score and FRC/TLC, suggestive of hyperinflation (table 3). Univariate analysis demonstrated that hyperinflation (increased FRC/TLC) was associated with low birth weight $\mathrm{z}$-score $(\mathrm{B}=-1.428 ; 95 \% \mathrm{CI}-2.802$ to -0.054 ; $\mathrm{p}=0.042$ ) and an increased duration of CPAP in the neonatal period independent of other respiratory support $(B=0.196$; $95 \%$ CI 0.056 to $0.335 ; \mathrm{p}=0.006$ ) (see online supplementary

Table 2 Neonatal information about the preterm participants

\begin{tabular}{|c|c|c|c|}
\hline & \multirow[b]{2}{*}{ Preterm } & \multicolumn{2}{|l|}{ Preterm } \\
\hline & & No BPD & BPD \\
\hline Gestational age (PMA) & $28.0(25.0,29.6)$ & $29.8(28.6,31.0)$ & $26.0(24.4,27.6)^{*}$ \\
\hline Birth weight (g) & $955(755,1335)$ & $1388(1186,1645)$ & $825(700,955)^{*}$ \\
\hline Birth weight z-score (mean, SD) & $-0.14(0.91)$ & $0.00(0.95)$ & $-0.22(0.88)$ \\
\hline Birth length $(\mathrm{cm})$ & $35.5(33.0,39.5)$ & $40.0(38.0,42.0)$ & $34.0(32.0,36.0)^{*}$ \\
\hline Duration of oxygen supplementation (days) & $48(2,92)$ & $1(0,3.8)$ & $85(59,103)^{*}$ \\
\hline Duration of mechanical ventilation (days) & $4(0,28)$ & $0(0,1)$ & $20(5,39)^{*}$ \\
\hline Duration of CPAP (days) & $6(1,18)$ & $1(0,3.7)$ & $14(4,24)^{*}$ \\
\hline Surfactant administered, n (\%) & $115(70.6)$ & $27(42.7)$ & $88(89.8)^{*}$ \\
\hline Antenatal steroids, n (\%) & $133(81.6)$ & $53(82.8)$ & $80(81.6)$ \\
\hline
\end{tabular}

* Represents significant difference between the preterm groups with and without BPD $(p<0.05)$.

Continuous neonatal variables are presented as median (IQR), except birth weight $\mathrm{z}$-score (mean, SD). Binary variables are expressed as $\mathrm{n}(\%)$.Birth weight $\mathrm{z}$-score was calculated from Fenton growth charts for preterm infants. ${ }^{23}$

BPD, bronchopulmonary dysplasia; PMA, postmenstrual age. 
Table 3 Lung function in healthy children and preterm children during mid-childhood

\begin{tabular}{|c|c|c|c|}
\hline & Term controls (reference) & Preterm & Mean difference $(95 \% \mathrm{Cl})$ \\
\hline \multicolumn{4}{|c|}{ Forced flows and volumes (spirometry) } \\
\hline n successful & 48 & 131 & \\
\hline $\mathrm{FEV}_{1}$ z-score & $0.04(0.90)$ & $-0.72(1.13)$ & $-0.76(-1.12 \text { to }-0.40)^{* *}$ \\
\hline $\mathrm{FEV}_{1} / \mathrm{FVC}$ z-score & $-0.27(0.92)$ & $-1.25(1.01)$ & $-0.98(-1.33 \text { to }-0.63)^{* *}$ \\
\hline $\mathrm{FEF}_{25-75}$ z-score & $-0.42(0.90)$ & $-1.46(1.11)$ & $-1.04(-1.42 \text { to }-0.67)^{* *}$ \\
\hline FVC z-score & $0.17(0.95)$ & $0.13(1.04)$ & $-0.04(-0.40$ to 0.33$)$ \\
\hline \multicolumn{4}{|c|}{ Lung volume and ventilation distribution (multiple breath washout) } \\
\hline n successful & 50 & 140 & \\
\hline $\mathrm{LCl}$ & $6.14(0.58)$ & $6.33(0.82)$ & $0.19(-0.06$ to 0.44$)$ \\
\hline FRC z-score & $-0.09(0.96)$ & $0.42(1.32)$ & $0.51(0.10 \text { to } 0.91)^{*}$ \\
\hline TLC z-score & $-0.16(0.85)$ & $-0.05(1.02)$ & $0.11(-0.21$ to 0.42$)$ \\
\hline RV z-score & $-0.45(1.10)$ & $-0.16(1.23)$ & $0.28(-0.11$ to 0.68$)$ \\
\hline $\mathrm{FRC} / \mathrm{TLC}(\%)$ & $50.36(6.65)$ & $52.80(7.49)$ & $2.44(0.07 \text { to } 4.81)^{*}$ \\
\hline RV/TLC (\%) & $21.29(6.18)$ & $22.79(7.02)$ & $1.50(-0.73$ to 3.72$)$ \\
\hline \multicolumn{4}{|l|}{ Gas exchange (DLCO) } \\
\hline n successful & 38 & 74 & \\
\hline $\mathrm{DL}_{\mathrm{CO}} \mathrm{z}$-score & $0.10(0.97)$ & $0.28(1.27)$ & $0.17(-0.29$ to 0.64$)$ \\
\hline $\mathrm{V}_{\mathrm{A}} \mathrm{z}$-score & $-0.72(1.16)$ & $-0.50(1.33)$ & $0.24(-0.27$ to 0.74$)$ \\
\hline $\mathrm{K}_{\mathrm{co}} \mathrm{z}$-score & $-0.56(0.86)$ & $-0.57(0.98)$ & $-0.02(-0.39$ to 0.36$)$ \\
\hline \multicolumn{4}{|c|}{ Respiratory system mechanics (forced oscillation technique) } \\
\hline n successful & 31 & 132 & \\
\hline $\mathrm{Rrs}_{8} \mathrm{z}$-score & $0.00(0.94)$ & $0.33(1.04)$ & $0.32(-0.08$ to 0.72$)$ \\
\hline $\mathrm{Xrs}_{8} \mathrm{z}$-score & $0.14(0.53)$ & $-0.43(0.99)$ & $-0.57(-0.94 \text { to }-0.21)^{*}$ \\
\hline AX z-score & $-0.44(0.85)$ & $0.29(1.15)$ & $0.72(0.29 \text { to } 1.16)^{* *}$ \\
\hline Fres z-score & $-0.18(1.26)$ & $0.64(1.23)$ & $0.82(0.31 \text { to } 1.33)^{*}$ \\
\hline
\end{tabular}

table S3). CPAP duration remained an independent predictor of hyperinflation in a multivariate analysis (see online supplementary table S3). Low birth weight z-score was also a significant predictor of increased RV/TLC (another marker of hyperinflation) such that RV/TLC (\%) was increased by 1.83 units per z-score decrease in birth weight $(95 \% \mathrm{CI}-3.106$ to $-0.557 ; \mathrm{p}=0.005$ )(see figure 1 and online supplementary table S3).

Gas exchange: None of the measures of gas exchange (diffusing capacity of the lung for carbon monoxide (DLCO)) were different between healthy children and those born preterm regardless of BPD diagnosis (table 3). Higher DLCO z-score was weakly predicted by increased duration of CPAP in the neonatal period independent of other respiratory support in a univariate analysis $(\mathrm{B}=0.038 ; 95 \% \mathrm{CI} 0.006$ to $0.070 ; \mathrm{p}=0.022)$. No other neonatal factors predicted impairment in gas exchange (see online supplementary table S4).

Respiratory system mechanics (forced oscillation technique (FOT)): Preterm children had worse peripheral lung mechanics than the healthy control group, as indicated by more negative respiratory system reactance at $8 \mathrm{~Hz}\left(\mathrm{Xrs}_{8}\right)$, increased area under the reactance curve $(A X)$ and increased resonant frequency $\left(f_{\text {res }}\right)$ (see table 3 and online supplementary table S1). Increased days of oxygen supplementation was associated with increased $f_{\text {res }}$ $(\mathrm{B}=0.010 ; 95 \%$ CI 0.000 to $0.019 ; \mathrm{p}=0.045)$ and $A X$ $(\mathrm{B}=0.009$; $95 \%$ CI 0.001 to $0.018 ; \mathrm{p}=0.035)$, where FOT outcomes were increased by approximately $0.07 \mathrm{z}$-scores for each week of supplemental oxygen exposure (see online supplementary table S5).
Respiratory symptoms and lung function: Participants with any reported respiratory symptoms in the 3 months prior to the study visit $(n=80)$ (see table 1$)$ had worse respiratory mechanics than those with no symptoms. Indeed, for every z-score increase in $A X$ and $z$-score decrease in $X r_{8}$, the likelihood of reported symptoms was increased $1.42(95 \%$ CI 1.024 to 1.973 ; $\mathrm{p}=0.036$ ) times and 1.62 times (OR $0.619 ; 95 \%$ CI 0.417 to $0.919 ; \mathrm{p}=0.017)$, respectively. There were no other differences in lung function between the preterm children with recent symptoms and those without.

\section{Lung structure in preterm children}

Structural abnormalities were present in $92 \%$ of all children born $\leq 32$ weeks gestation (table 4). Children with BPD had more extensive structural lung disease on chest CT scan compared with children without BPD (see table 3 for median (IQR)), with total CT score ranging from 0 to 17 for the preterm group and 0 to 26 for the BPD group out of a maximum score of $50 .^{21}$

Linear and triangular subpleural opacities were the most commonly identified abnormalities and were more severe in children with BPD. Areas of collapse/consolidation and hypoattenuation on the inspiratory CT scan were also more extensive in the BPD group. No differences between the BPD and non-BPD groups were observed for the other radiological findings (see figure 2 for examples of radiological abnormalities).

Children with recent respiratory symptoms (67 of 127 scans) had significantly higher total CT scores (median $=7$; IQR $=4-12$ ) than children without recent symptoms $(4 ; 2-7 ; \mathrm{p}=0.003)$, 

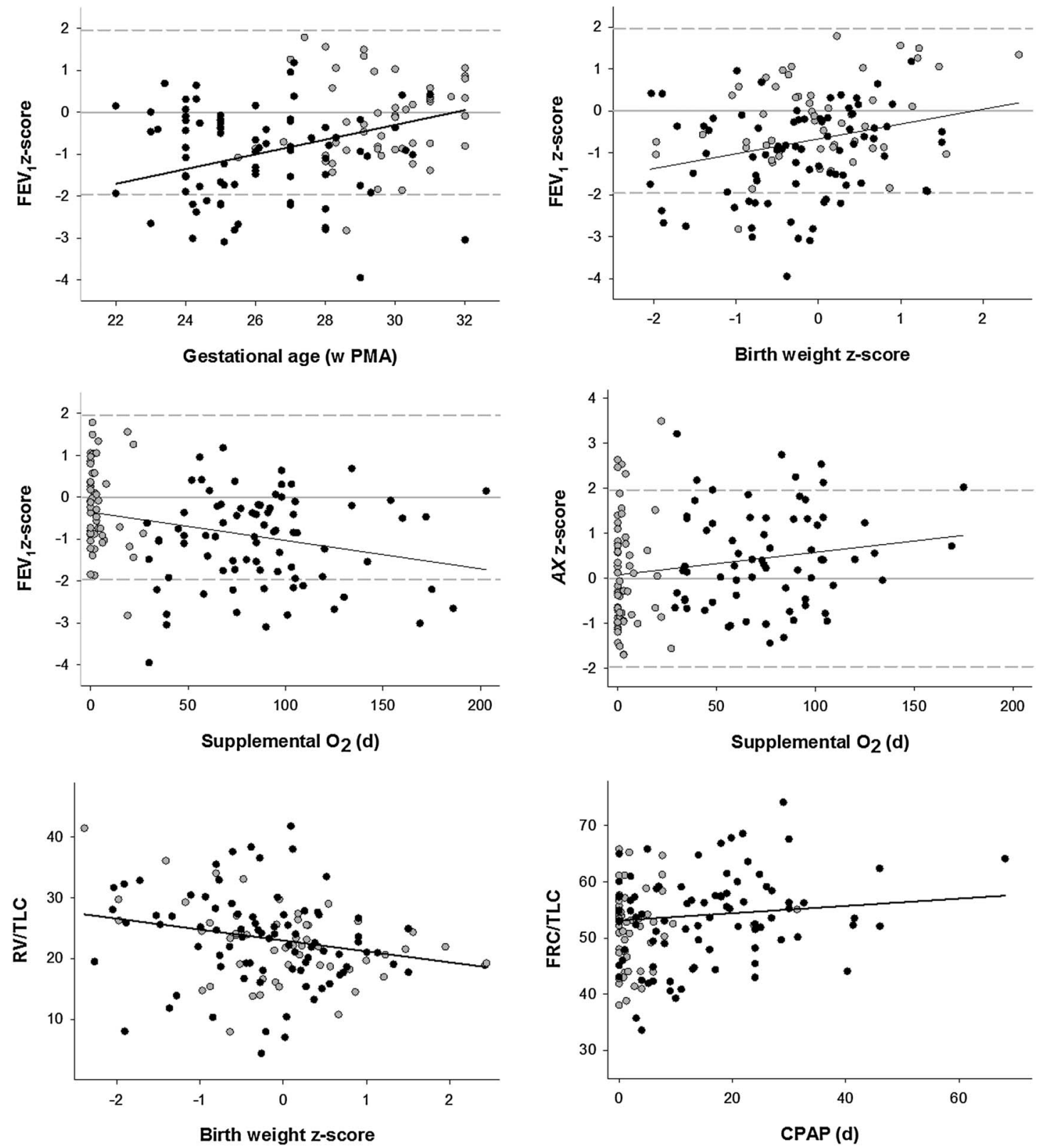

Figure 1 Neonatal factors influencing lung function in preterm children at 9-11 years. Lung function is expressed as z-scores, except for functional residual capacity (FRC)/TLC (\%) and RV/TLC (\%). Lung function is plotted against neonatal factors for children born preterm with a neonatal classification of bronchopulmonary dysplasia (BPD) (black) and those without BPD (grey). Grey dashed lines indicate 1.96 z-scores.

largely owing to increased scores for hypoattenuated areas on inspiration $(0 ; 0,2 ; \mathrm{p}=0.027)$ and bronchial wall thickening $(1 ; 0,3 ; \mathrm{p}=0.021)$.

Lower GA, lower birth weight z-score, neonatal sepsis and increased duration of respiratory support (oxygen supplementation and mechanical ventilation) were generally associated with more extensive structural abnormalities (total CT score, linear and triangular subpleural opacities, hypoattenuation on inspiration and collapse/consolidation score) (see figure 3 and online supplementary table S6). None of the neonatal clinical variables explained the extent of hypoattenuated areas of the lung during expiration or bronchial wall thickening.

Multivariate analysis suggested that each additional week of gestation was associated with a 0.64 -unit decrease in total CT score $(95 \%$ CI -0.99 to $-0.29 ; \mathrm{p}<0.001)$, resulting from decreased scores for subpleural opacities $(B=-0.330 ; 95 \%$ CI -0.463 to $-0.196 ; \mathrm{p}<0.001)$ and hypoattenuation on inspiration $(\mathrm{B}=-0.113 ; 95 \% \mathrm{CI}-0.211$ to $-0.016 ; \mathrm{p}=0.023)$. Additionally, after accounting for GA each week of mechanical ventilation was associated with a 0.55 -unit increase in total CT score $(95 \%$ CI 0.015 to $0.142 ; \mathrm{p}=0.078)$, largely a result of increased liner/triangular subpleural opacity score $(B=0.029$, $95 \%$ CI 0.006 to $0.052 ; p=0.015)$. See online supplementary table $\mathrm{S} 6$ for further details.

A random subset of CT scans $(\mathrm{N}=20)$ were rescored a mean (SD) time of 6.1 (1.6) years after first scoring, by the same observers. The intraobserver reliability was excellent with an Intraclass Correlation Coefficient (ICC) of 0.81 (95\% CI 0.51 to 0.93 ) and an absolute agreement ICC of 0.76 (0.36 to 0.91 ).

Lung structure/function relationships in preterm children Obstructive lung disease was evident in children with more extensive structural abnormalities on CT scan. $\mathrm{FEV}_{1}, \mathrm{FEV}_{1} / \mathrm{FVC}$ and $\mathrm{FEF}_{25-75}$ z-scores were decreased by approximately 0.1 
Table 4 The presence and extent of chest CT abnormalities in children born very preterm

\begin{tabular}{|c|c|c|c|c|}
\hline & Preterm & $\begin{array}{l}\text { Preterm without BPD } \\
(n=50)\end{array}$ & $\begin{array}{l}\text { Preterm with BPD } \\
(n=83)\end{array}$ & $\begin{array}{l}\text { Hodges-Lehman median } \\
\text { difference }(95 \% \mathrm{Cl})\end{array}$ \\
\hline \multicolumn{5}{|c|}{ Structural abnormalities on chest CT } \\
\hline Presence, n participants (\%) & $123(92)$ & $44(88)$ & $79(95)$ & \\
\hline Extent (total CT score) & $5(3-9)$ & $4(1-7)$ & $6(4-11)$ & $2(1$ to 4$) ; p=0.008^{*}$ \\
\hline \multicolumn{5}{|c|}{ Linear/triangular subpleural opacities } \\
\hline Presence & $112(84 \%)$ & $39(78 \%)$ & $73(88 \%)$ & \\
\hline Extent & $3(1-5)$ & $2(1-3)$ & $3(2-6)$ & 2 (1 to 2$) ; p<0.001^{*}$ \\
\hline \multicolumn{5}{|c|}{ Decreased pulmonary attenuation-inspiration } \\
\hline Presence & $40(30 \%)$ & $9(18 \%)$ & $31(37 \%)^{*}$ & \\
\hline Extent & $0(0-1)$ & $0(0-0)$ & $0(0-1)$ & $0(0$ to 0$) ; p=0.013^{*}$ \\
\hline \multicolumn{5}{|c|}{ Decreased pulmonary attenuation-expiration } \\
\hline Presence & $58(44 \%)$ & $23(46 \%)$ & $35(42 \%)$ & \\
\hline Extent & $0(0-2)$ & $0(0-2)$ & $0(0-2)$ & 0 (0 to 0$) ; p=0.926$ \\
\hline \multicolumn{5}{|l|}{ Decreased bronchial: arterial ratio } \\
\hline Presence & $2(2 \%)$ & $1(2 \%)$ & $1(1 \%)$ & \\
\hline Extent & $0(0-0)$ & $0(0-0)$ & $0(0-0)$ & 0 (0 to 0$) ; p=0.708$ \\
\hline \multicolumn{5}{|l|}{ Bronchiectasis } \\
\hline Presence & $12(9 \%)$ & $4(8 \%)$ & $8(10 \%)$ & \\
\hline Extent & $0(0-0)$ & $0(0-0)$ & $0(0-0)$ & $0(0$ to 0$) ; p=0.801$ \\
\hline \multicolumn{5}{|l|}{ Bronchial wall thickening } \\
\hline Presence & $58(44 \%)$ & $20(40 \%)$ & $38(46 \%)$ & \\
\hline Extent & $0(0-3)$ & $0(0-2)$ & $0(0-3)$ & $0(0$ to 0$) ; p=0.473$ \\
\hline \multicolumn{5}{|l|}{ Bullae } \\
\hline Presence & $2(2 \%)$ & $0(0 \%)$ & $2(2 \%)$ & \\
\hline Extent & $0(0-0)$ & $0(0-0)$ & $0(0-0)$ & $0(0$ to 0$) ; p=0.271$ \\
\hline \multicolumn{5}{|l|}{ Emphysema } \\
\hline Presence & $4(3 \%)$ & $0(0 \%)$ & $4(5 \%)$ & \\
\hline Extent & $0(0-0)$ & $0(0-0)$ & $0(0-0)$ & $0(0$ to 0$) ; p=0.116$ \\
\hline \multicolumn{5}{|l|}{ Collapse/consolidation } \\
\hline Presence & $15(11 \%)$ & $1(2 \%)$ & $14(17 \%)^{*}$ & \\
\hline Extent & $0(0-0)$ & $0(0-0)$ & $0(0-0)$ & $0(0$ to 0$) ; p=0.008^{*}$ \\
\hline
\end{tabular}

z-scores for each increase in linear/triangular subpleural opacities, bronchial wall thickening and hypoattenuation score during an inspiratory chest CT $(\mathrm{p}<0.05)$ (see figure 4 and online supplementary table S7).

Lung volumes were largely unaffected by chest CT abnormalities with the exception of areas of lung collapse/consolidation in preterm children that predicted reduced $\mathrm{RV} \mathrm{z}$-score $(\mathrm{B}=-1.156 ; 95 \% \mathrm{CI}-1.892$ to $-0.420 ; \mathrm{p}=0.002)$ and $\mathrm{RV} /$ TLC $(B=-6.779 ; 95 \% \mathrm{CI}-10.991$ to $-2.566 ; \mathrm{p}=0.002)$ (see online supplementary table S8). Additionally, increased TLC was apparent in children with bronchiectasis $(B=0.202 ; 95 \% \mathrm{CI}$ 0.020 to $0.384 ; \mathrm{p}=0.030$ ).

KCO was decreased by $0.23 \mathrm{z}$-scores in preterm children for each unit increase in hypoattenuation on an inspiratory chest CT $(B=-0.233 ; 95 \%$ CI -0.406 to $-0.061 ; \mathrm{p}<0.009$ ) (see online supplementary table S9). Altered respiratory system mechanics was not independently predicted by structural lung damage on chest CT (see online supplementary table S10).

\section{DISCUSSION}

This study provides the most comprehensive assessment to date of lung structure and function in school-aged children born very preterm ( $\leq 32$ weeks gestation) during the surfactant era. We show that preterm children have a significant burden of respiratory disease at mid-childhood with structural abnormalities present in almost all preterm children and recent respiratory symptoms reported in approximately half of the cohort. Lung function is also lower in children born preterm, and is associated with increased structural lung damage.

We show significant airway obstruction in children born very preterm with reductions in $\mathrm{FEV}_{1}, \mathrm{FEF}_{25-75}$ and $\mathrm{FEV}_{1} / \mathrm{FVC}$, and further reductions in children with BPD. Increased airway obstruction is in line with other studies that have measured spirometry in preterm children with both new 81024 and old ${ }^{25} 26$ BPD. Findings of reduced forced expiratory flows and volumes with stable FVC are suggestive of reduced airway calibre in this population and likely results from chronic airway inflammation, airway remodelling and/or reduced parenchymal tethering. Almost half of the very preterm children in this study had evidence of bronchial wall thickening on chest CT that we speculate reflects postinflammatory changes and/or ongoing airway inflammation. Indeed, children with bronchial wall thickening had significantly worse obstructive lung disease and more respiratory symptoms than their peers, which may indicate that closer monitoring of this group is warranted. Additionally, the small airways may be particularly at risk from oxygen toxicity 

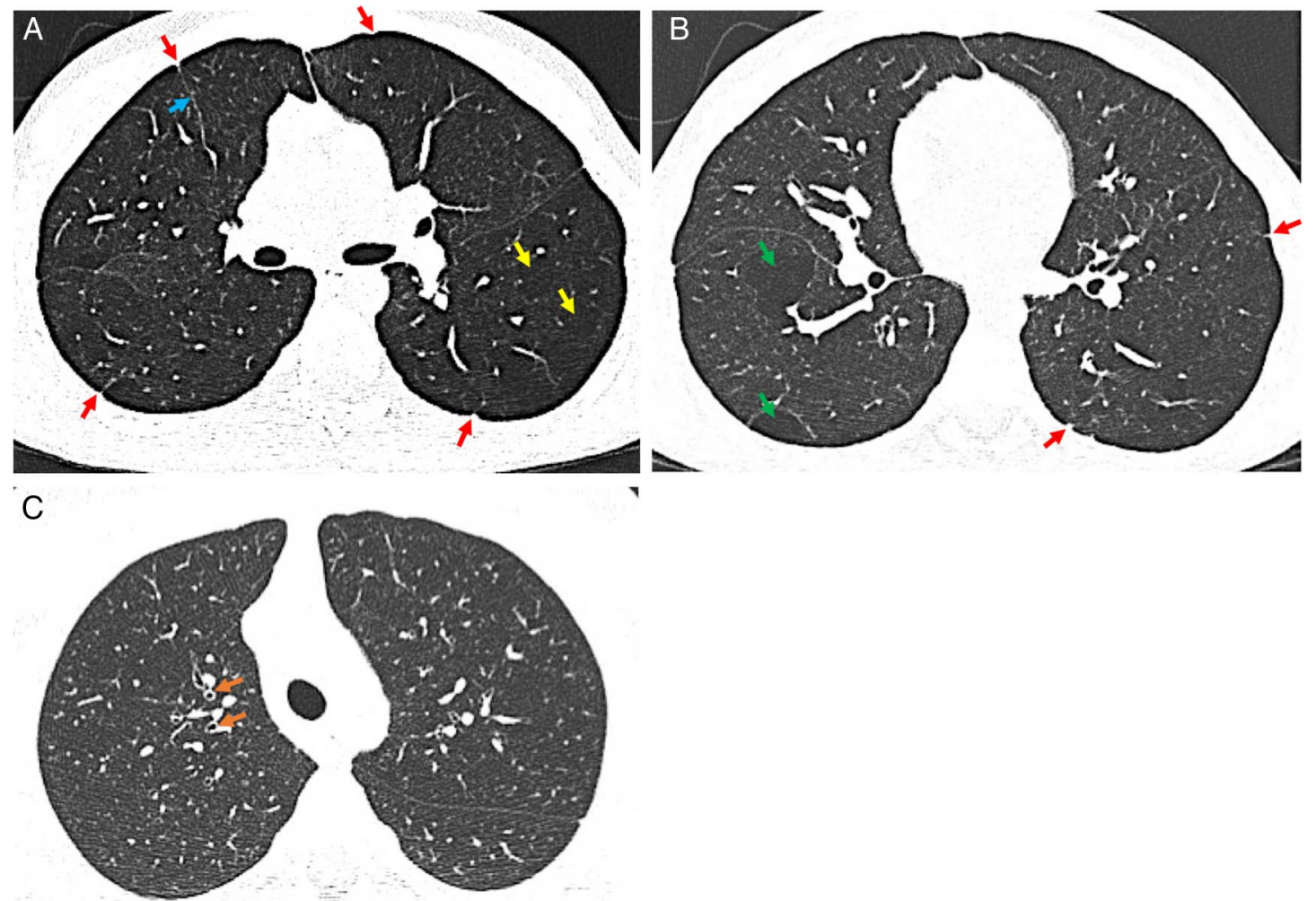

Figure 2 Chest CT abnormalities in contemporary bronchopulomary dysplasia. All images were acquired during inspiration. Images A and B are from an 11-year-old male (27 weeks gestation) highlighting triangular subpleural (red) and linear (blue) opacities, areas of hypoattenuation/mosaic perfusion (yellow) and emphysema (green). Image $C$ is from an 11-year-old male (25 weeks gestation) and highlights bronchial wall thickening (orange).
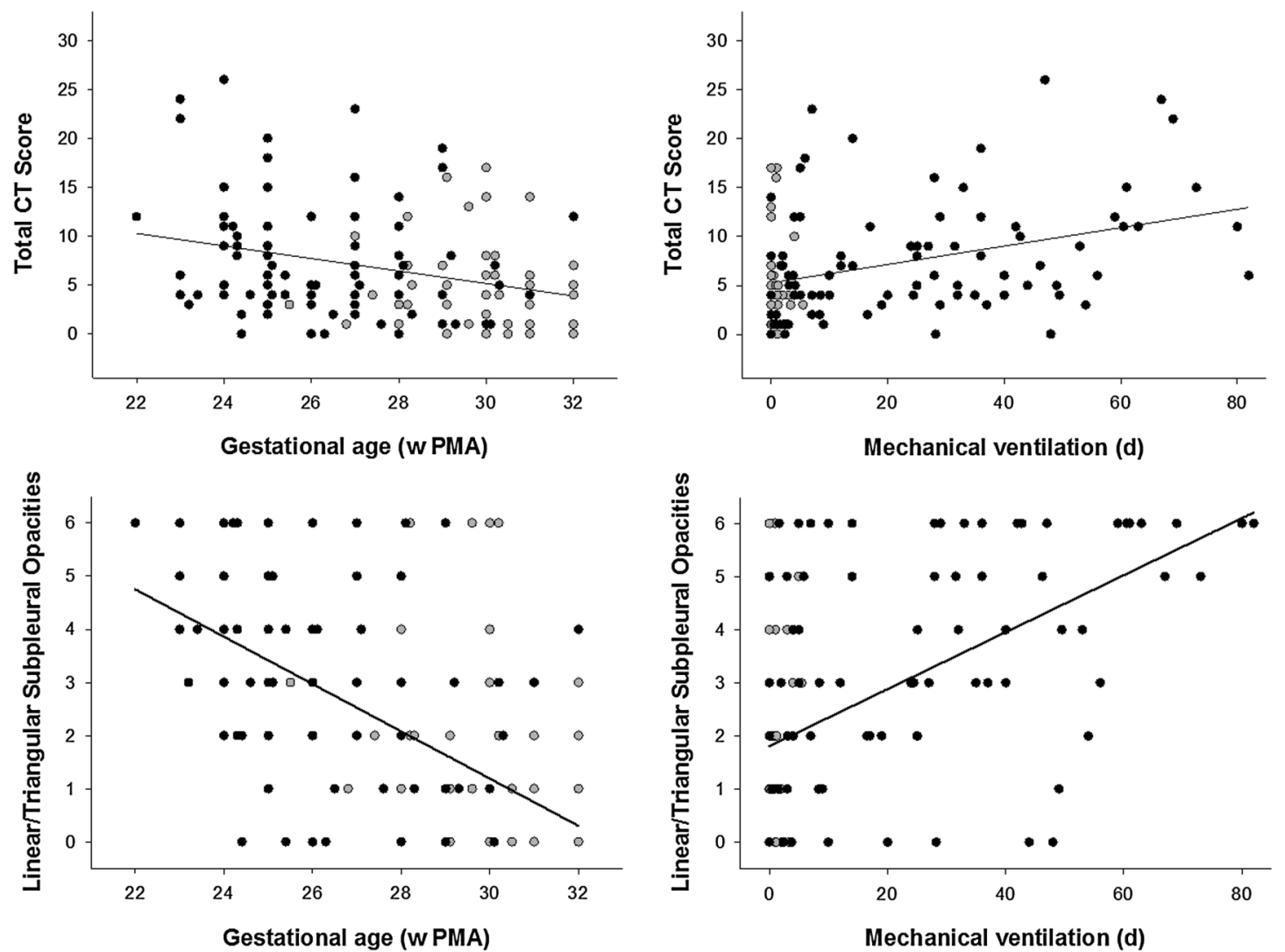

Figure 3 Neonatal factors influencing lung structure in preterm children at 9-11 years. Total CT score (max 50) and extent score for linear and triangular subpleural opacities (max 6) are plotted against gestational age, and days of mechanical ventilation for children born preterm with a neonatal classification of bronchopulmonary dysplasia (BPD) (black) and those without BPD (grey). 

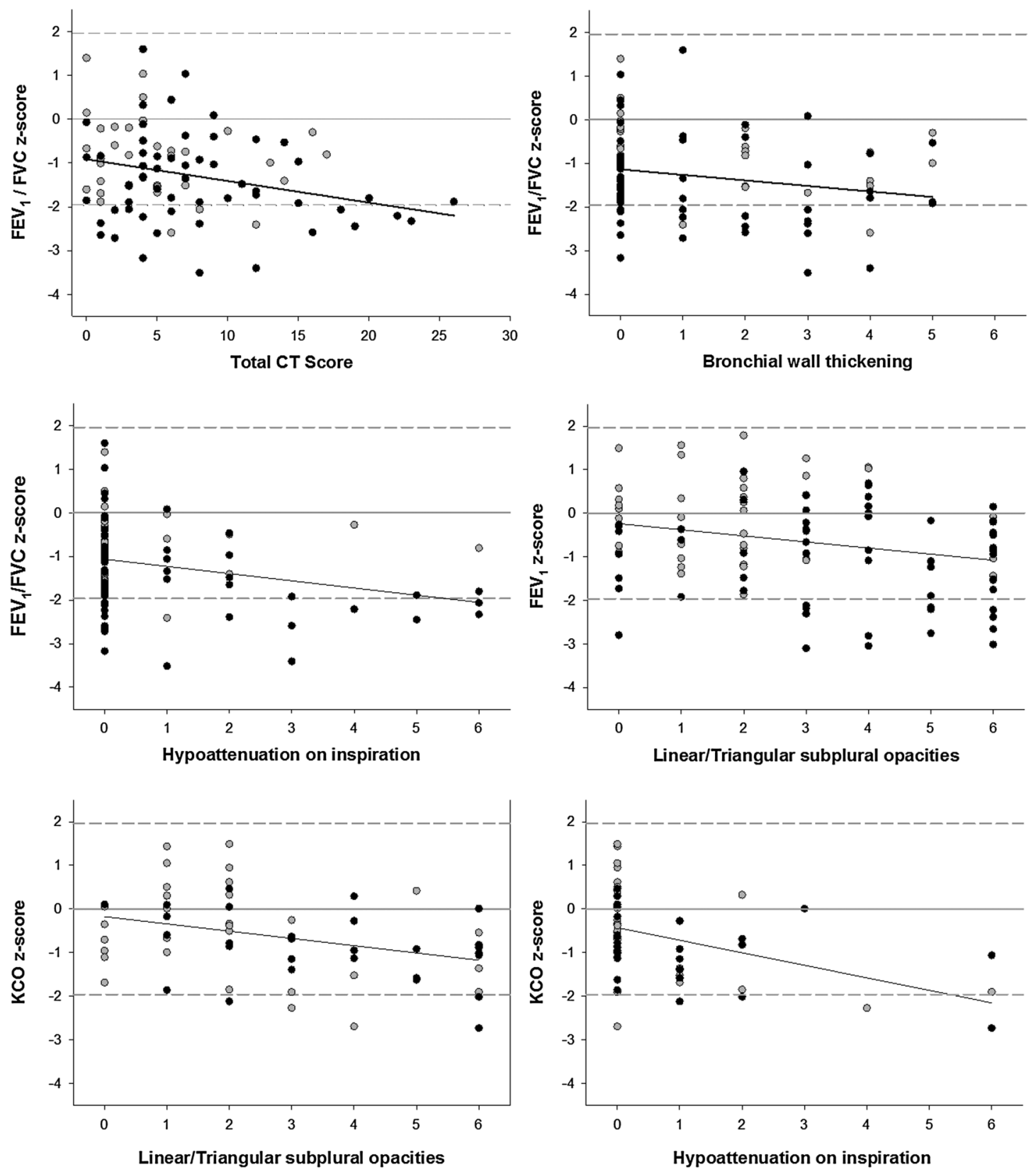

Figure 4 Relationships between lung function and lung structure in preterm children. Lung function, expressed as z-scores, is plotted against chest CT outcomes for preterm children with (black) and without (grey) bronchopulmonary dysplasia.

during the neonatal period, with reduced midexpiratory flows evident in those with longer exposures to oxygen.

The morphological changes in the lungs of children born very preterm, such as larger simplified alveoli, suggest that changes in lung volume and ventilation inhomogeneity should be observed in this population. However, previous studies are inconclusive, with some reporting a degree of air trapping (elevated RV/TLC) in $\mathrm{BPD}^{27-29}$ and others failing to discriminate preterm children from healthy controls. ${ }^{30} 31$ In this study, lung volumes were generally not different between preterm children with and without $\mathrm{BPD}$, although air trapping was associated with being born small for GA and the increased duration of CPAP, perhaps indicating that these children are more prone to airway collapse and consequent gas trapping. Interestingly, those preterm children with bronchiectasis and areas of lung collapse or consolidation on chest CT had smaller lung volumes consistent with these pathologies. Differences between studies may reflect the heterogeneity of lung disease in preterm children and the cohorts associated with each of these studies. By including participants from a wide spectrum of GA and neonatal lung disease severity, we may have dampened the signal when compared with studies that highlight the extreme preterm phenotype such as the EPICure data ( $\leq 25$ weeks GA). ${ }^{27}$

Prematurity and lung injury during the neonatal period impair growth, branching and distribution of the pulmonary vasculature. $^{32} 33$ Surprisingly, no gas transfer measures were different in children born preterm, likely indicating that diffusion distances across the respiratory epithelium are similar between term and preterm children. Additionally, DLCO outcomes were not associated with neonatal factors that promote lung injury, such as mechanical ventilation or exposure to supplemental oxygen, or antenatal corticosteroid treatment which promotes thinning of alveolar walls ${ }^{34}$ and potential increased efficiency of gas exchange. The few studies of lung function in the 
postsurfactant era portray conflicting results for DLCO: some studies show decreased DLCO in preterm children with $\mathrm{BPD}^{27} 35$ while others fail to detect a difference. ${ }^{31}$ Our findings may be influenced by the difficulty obtaining acceptable and repeatable DLCO measures in children with BPD compared with the term and preterm without BPD groups. Children with BPD who were born with low birth weight $z$-scores were less likely to achieve acceptable DLCO results at school age and were consequently under-represented in the analyses of gas exchange, biasing the results. The inability to obtain acceptable and repeatable DLCO in this population may be a manifestation of the cognitive and behavioural deficits, such as hyperactivity, inattention and dysfunction in executive functioning, known to persist in very and extremely low birth weight infants (see ref. 36 for review).

In contrast to studies of young adults with old BPD, ${ }^{37}$ emphysema was detected in only $5 \%$ of this cohort of preterm children. However, almost half of the children in this study have areas of decreased pulmonary attenuation on the chest CT scan that may reflect pre-emphysematous changes to the lung (which may be progressive). Alternatively, hypoattenuation may be related to disrupted pulmonary vascularisation and reduced alveolar complexity leading to decreased surface area for gas exchange seen in postmortem specimens of infants and children with BPD. ${ }^{38}$ Regardless, those children who have hypoattenuated areas on inspiratory CT scan have more airway obstruction (lower $\mathrm{FEV}_{1} / \mathrm{FVC}$ ) and reduced KCO. Consequently, this specific group of children may warrant follow-up to determine if their lung disease is progressive.

We show that structural abnormalities are very common (92\%) in the lungs of children born preterm. Structural damage was more extensive in children of lower GA who received more oxygen and mechanical ventilation in the neonatal period, which is consistent with the notion that more immature and fragile lungs have increased susceptibility to injury. Only two small other studies (of 32 and 26 subjects, respectively) report chest CT findings in long-term survivors of preterm birth in the surfactant era. ${ }^{24} 39$ Using the same methodology and scoring system, Aukland et al reported lower median (IQR) total CT scores (3.0 $(1.75-5.0))$ in a cohort of preterm children born in 1991-1992 than the scores reported from our cohort. While developed specifically for survivors of preterm birth, the extent of the chest CT findings is likely to be limited by the insensitivity of the scoring method since the scoring method does not allow for multiple presentations within the same lobe. Additionally, both studies performed only limited slice scans to minimise the radiation dose and therefore may have underestimated the extent of the lung abnormalities. ${ }^{40}$ We are also unable to comment on the likelihood of observing any of these abnormalities in the healthy control population. However, these abnormalities are, by definition, pathological and unlikely to be present in the control population.

We show heterogeneous impairments in lung structure and lung function at 9-11 years in children born $\leq 32$ weeks gestation. Prolonged $\mathrm{O}_{2}$ dependence in the neonatal period alone does not accurately predict which children will go on to have increased pulmonary morbidity, despite underpinning the clinical definition of BPD. Our data show that some infants with BPD may have normal lung function and no respiratory symptoms. Conversely, respiratory symptoms and pulmonary function deficits may appear in children born preterm who did not require prolonged ventilatory support during infancy. Regardless, we have shown that structural and functional respiratory limitations are evident in very preterm survivors during mid-childhood. It remains unknown whether the involvement of the peripheral lung is related to structural abnormalities due to preterm birth per se, such as fewer larger alveoli, or whether the changes we observe are pre-emphysematous changes. Determining whether the structural and functional abnormalities are progressive and what the clinical implication of such decline might mean for the health of these children as they age remains a priority for future investigations.

\section{Author affiliations}

${ }^{1}$ Telethon Kids Institute, Perth, WA, Australia

${ }^{2}$ Centre for Child Health Research, University of Western Australia, Perth, WA, Australia

${ }^{3}$ School of Paediatrics and Child Health, University of Western Australia, Perth, WA, Australia

${ }^{4}$ Department of Respiratory and Sleep Medicine, Princess Margaret Hospital for Children, Perth, WA, Australia

${ }^{5}$ School of Physiotherapy and Exercise Science, Faculty of Health Sciences, Curtin University, Perth, WA, Australia

${ }^{6}$ Diagnostic Imaging, Princess Margaret Hospital for Children, Perth, WA, Australia ${ }^{7}$ Department of Anatomy, Physiology and Human Biology, University of Western Australia, Perth, WA, Australia

Contributors ACW, JJP and GLH: study design. SJS, KML, CAO and GLB: data collection, lung function analysis and database entry. CM and ACW: CT scoring. SJS, JJP and GLH: statistical analysis and data interpretation. SJS, KLM and GH: manuscript preparation. All authors: revision of manuscript.

Funding NHMRC (APP634519), Princess Margret Hospital Foundation and Raine Medical Foundation. SJS (APP1073301), JJP (APP1077691) and GLH (APP1025550) are supported by NHMRC Fellowships.

Competing interests None declared.

Patient consent Obtained.

Ethics approval Princess Margaret Hospital Human Research Ethics Committee.

Provenance and peer review Commissioned; externally peer reviewed.

\section{REFERENCES}

1 Northway WH Jr, Rosan RC, Porter DY. Pulmonary disease following respirator therapy of hyaline-membrane disease. Bronchopulmonary dysplasia. N Engl J Med 1967;276:357-68.

2 Kamath $B D$, Macguire ER, McClure EM, et al. Neonatal mortality from respiratory distress syndrome: lessons for low-resource countries. Pediatrics 2011;127:1139-46.

3 Blencowe $\mathrm{H}$, Cousens S, Oestergaard MZ, et al. National, regional, and worldwide estimates of preterm birth rates in the year 2010 with time trends since 1990 for selected countries: a systematic analysis and implications. Lancet 2012;379:2162-72.

4 Jobe AJ. The new BPD: an arrest of lung development. Pediatr Res 1999;46:641-3.

5 Husain AN, Siddiqui NH, Stocker JT. Pathology of arrested acinar development in postsurfactant bronchopulmonary dysplasia. Hum Pathol 1998;29:710-17.

6 Elder DE, Hagan R, Evans SF, et al. Hospital admissions in the first year of life in very preterm infants. J Paediatr Child Health 1999;35:145-50.

7 Pramana IA, Latzin P, Schlapbach LJ, et al. Respiratory symptoms in preterm infants: burden of disease in the first year of life. Eur J Med Res 2011;16:223-30.

8 Fawke J, Lum S, Kirkby J, et al. Lung function and respiratory symptoms at 11 years in children born extremely preterm: the EPICure study. Am J Respir Crit Care Med 2010;182:237-45.

9 Vollsæter M, Skromme K, Satrell E, et al. Children Born Preterm at the Turn of the Millennium Had Better Lung Function Than Children Born Similarly Preterm in the Early 1990s. PLOS ONE 2015;10:e0144243.

10 Hacking DF, Gibson AM, Robertson C, et al. Respiratory function at age 8-9 after extremely low birthweight or preterm birth in Victoria in 1997. Pediatr Pulmonol 2013;48:449-55

11 Verheggen M, Wilson AC, Pillow JJ, et al. Respiratory function and symptoms in young preterm children in the contemporary era. Pediatr Pulmonol 2016;51:1347-55.

12 Jobe AH, Bancalari E. Bronchopulmonary dysplasia. Am J Respir Crit Care Med 2001;163:1723-9.

13 MacIntyre N, Crapo RO, Viegi G, et al. Standardisation of the single-breath determination of carbon monoxide uptake in the lung. Eur Respir $J$ 2005;26:720-35.

14 Miller MR, Hankinson J, Brusasco V, et al. Standardisation of spirometry. Eur Respir J 2005;26:319-38. 
15 Oostveen $\mathrm{E}$, MacLeod $\mathrm{D}$, Lorino $\mathrm{H}$, et al. The forced oscillation technique in clinical practice: methodology, recommendations and future developments. Eur Respir J 2003;22:1026-41.

16 Wanger J, Clausen JL, Coates A, et al. Standardisation of the measurement of lung volumes. Eur Respir J 2005;26:511-22.

17 Cook CD, Hamann JF. Relation of lung volumes to height in healthy persons between the ages of 5 and 38 years. J Pediatr 1961;59:710-14.

18 Quanjer PH, Stanojevic S, Cole TJ, et al. Multi-ethnic reference values for spirometry for the 3-95-yr age range: the global lung function 2012 equations. Eur Respir J 2012:40:1324-43.

19 Kim YJ, Hall GL, Christoph K, et al. Pulmonary diffusing capacity in healthy caucasian children. Pediatr Pulmonol 2012;47:469-75.

20 Calogero C, Simpson SJ, Lombardi E, et al. Respiratory impedance and bronchodilator responsiveness in healthy children aged 2-13 years. Pediatr Pulmonol 2013;48:707-15.

21 Aukland SM, Rosendahl K, Owens CM, et al. Neonatal bronchopulmonary dysplasia predicts abnormal pulmonary HRCT scans in long-term survivors of extreme preterm birth. Thorax 2009;64:405-10.

22 Powell CV, McNamara P, Solis A, et al. A parent completed questionnaire to describe the patterns of wheezing and other respiratory symptoms in infants and preschool children. Arch Dis Child 2002;87:376-9.

23 Fenton TR, Kim JH. A systematic review and meta-analysis to revise the Fenton growth chart for preterm infants. BMC Pediatr 2013;13:59.

24 Broström EB, Thunqvist $P$, Adenfelt $G$, et al. Obstructive lung disease in children with mild to severe BPD. Respir Med 2010;104:362-70.

25 Northway WH Jr, Moss RB, Carlisle KB, et al. Late pulmonary sequelae of bronchopulmonary dysplasia. N Engl J Med 1990;323:1793-9.

26 Vrijlandt EJ, Gerritsen J, Boezen HM, et al. Lung function and exercise capacity in young adults born prematurely. Am J Respir Crit Care Med 2006;173:890-6.

27 Lum S, Kirkby J, Welsh L, et al. Nature and severity of lung function abnormalities in extremely pre-term children at 11 years of age. Eur Respir J 2011;37:1199-207.
28 Korhonen P, Laitinen J, Hyödynmaa E, et al. Respiratory outcome in school-aged, very-low-birth-weight children in the surfactant era. Acta Paediatr 2004;93:316-21.

29 Smith LJ, van Asperen PP, McKay KO, et al. Reduced exercise capacity in children born very preterm. Pediatrics 2008;122:e287-93.

30 Schulzke SM, Hall GL, Nathan EA, et al. Lung volume and ventilation inhomogeneity in preterm infants at 15-18 months corrected age. J Pediatr 2010;156:542-9. e2.

31 Vom Hove M, Prenzel F, Uhlig HH, et al. Pulmonary outcome in former preterm, very low birth weight children with bronchopulmonary dysplasia: a case-control follow-up at school age. J Pediatr 2014;164:40-5.e4.

32 De Paepe ME, Mao Q, Powell J, et al. Growth of pulmonary microvasculature in ventilated preterm infants. Am J Respir Crit Care Med 2006;173:204-11.

33 Coalson JJ. Pathology of new bronchopulmonary dysplasia. Semin Neonatol 2003;8:73-81.

34 Willet $\mathrm{KE}$, Jobe $\mathrm{AH}$, Ikegami $\mathrm{M}$, et al. Lung morphometry after repetitive antenatal glucocorticoid treatment in preterm sheep. Am J Respir Crit Care Med 2001;163:1437-43.

35 Cazzato S, Ridolfi L, Bernardi F, et al. Lung function outcome at school age in very low birth weight children. Pediatr Pulmonol 2013;48:830-7.

36 Saigal S, Doyle LW. An overview of mortality and sequelae of preterm birth from infancy to adulthood. Lancet 2008;371:261-9.

37 Wong PM, Lees AN, Louw J, et al. Emphysema in young adult survivors of moderate-to-severe bronchopulmonary dysplasia. Eur Respir J 2008;32:321-8.

38 Sobonya RE, Logvinoff MM, Taussig LM, et al. Morphometric analysis of the lung in prolonged bronchopulmonary dysplasia. Pediatr Res 1982;16:969-72.

39 Aukland SM, Halvorsen T, Fosse KR, et al. High-resolution CT of the chest in children and young adults who were born prematurely: findings in a population-based study. AJR Am J Roentgenol 2006;187:1012-18.

40 de Jong PA, Nakano Y, Lequin MH, et al. Dose reduction for $\mathrm{CT}$ in children with cystic fibrosis: is it feasible to reduce the number of images per scan? Pediatr Radiol 2006;36:50-3. 